\title{
Characterisation and antibiotic susceptibilities of Streptobacillus moniliformis
}

\author{
R. EDWARDS and R. G. FINCH*
} Department of Microbiology and Public Health Laboratory, University Hospital, Queen's Medical Centre,
Nottingham NG7 2UH and "Department of Microbial Diseases, City Hospital, Nottingham NG5 1 PB

\begin{abstract}
Summary. The characteristics of seven strains of Streptobacillus moniliformis, including four isolates from a recent outbreak of Haverhill fever, are reported. Acid production from carbohydrates was uniform apart from variable reactions with mannose and salicin. Enzymatic reactions determined by the API ZYM system and fatty-acid profiles were generally consistent and may be of value in the rapid identification of $S$. moniliformis. Penicillin was the most active of the antibiotics tested in vitro, which supports its use as the drug of choice in the treatment of Haverhill fever.
\end{abstract}

\section{Introduction}

Streptobacillus moniliformis is a commensal of the nasopharynx of various rodents, especially rats, and the organism may also be excreted in the urine. It causes Haverhill fever in man and with Spirillum minus is responsible for rat bite fever (Watkins, 1946). The first outbreak of Haverhill fever in Britain was reported recently, renewing interest in S. moniliformis (Shanson et al, 1983). However, because infection is rare, problems of isolation and identification may arise in the clinical laboratory. Penicillin has been considered to be the drug of choice, with tetracycline, streptomycin and chloramphenicol as alternative agents (Roughgarden, 1965), but few in-vitro antibiotic-susceptibility studies have been reported, particularly against a range of more recently introduced antibiotics (Smith and Sampson, 1960).

In this report we present the characteristics of seven strains of $S$. moniliformis, including four isolates from a recent outbreak of Haverhill fever. Carbohydrate reactions, enzymatic activities, cellular fatty-acid profiles, $\beta$-lactamase production and minimum inhibitory concentrations (MIC) of nine antibiotics have been studied.

\section{Materials and methods}

\section{S. moniliformis strains}

Four strains isolated from the blood of patients in the recent outbreak of Haverhill fever (Shanson et al., 1983) and reference strains NCTC 10651 (type strain, ATCC 14647), NCTC 10773 and NCTC 11194 were studied.

Received 10 Oct. 1984; accepted 13 Mar. 1985.

\section{Acid production from carbohydrates}

The carbohydrates examined were: adonitol, arabinose, dextrin, dulcitol, erythritol, D-fructose, D-galactose, glucose, inositol, inulin, lactose, maltose, mannitol, mannose, raffinose, rhamnose, salicin, sorbitol, sucrose, trehalose and xylose. A $1 \%$ solution of each carbohydrate was prepared in Nutrient Broth (Oxoid) and dispensed in $4-\mathrm{ml}$ volumes. After sterilisation, $0.02 \mathrm{ml}$ of sterile horse serum (Oxoid) was added. The carbohydrate broths were inoculated with $0.04 \mathrm{ml}$ of a suspension of the test strain prepared by harvesting cells from a culture on blood agar (Blood Agar Base No. 2, Oxoid, with 7\% defibrinated horse blood, Tissue Culture Services, Slough) into nutrient broth to give $c .10^{8} \mathrm{cfu} / \mathrm{ml}$. Two sets of controls were included: (1) without carbohydrates and (2) without test strain suspensions. The inoculated carbohydrate broths and controls were incubated with caps loosened at $37^{\circ} \mathrm{C}$ in an atmosphere containing $\mathrm{CO}_{2} 5 \%$. After incubation for 3 days, $0.02 \mathrm{ml}$ of phenol red indicator was added and the colour reactions recorded. Incubation was continued for 4 more days and any subsequent colour change noted.

\section{Enzymatic activities}

The strains were tested with the API ZYM system (API Laboratory Products Ltd, Basingstoke, Hampshire), a semi-quantitative micro-method, in accordance with the manufacturer's instructions. Cells were harvested from blood agar after incubation for $48 \mathrm{~h}$ at $37^{\circ} \mathrm{C}$ in an atmosphere containing $\mathrm{CO}_{2} 5 \%$ and washed in saline before use. The enzymes tested are listed in table II.

\section{Fatty-acid analysis}

The strains were grown on blood agar for $48 \mathrm{~h}$ at $37^{\circ} \mathrm{C}$ in $\mathrm{CO}_{2} 5 \%$. Cells were harvested with a bent glass rod and washed twice in sterile saline. Saponification, methylation and extraction of the fatty acids were performed as 
described by Moss and Dees (1975). A Perkin-Elmer Sigma 3 gas chromatograph with flame-ionisation detectors and glass columns packed with $3 \% \mathrm{OV}-1$ on Chromosorb w.hp 100-120 was used to analyse 1- $\mu$ l amounts of fatty-acid extracts. The oven temperature was programmed to hold the initial temperature $160^{\circ} \mathrm{C}$ for $2 \mathrm{~min}$ and then increase at a rate of $4^{\circ} \mathrm{C} / \mathrm{min}$ to $220^{\circ} \mathrm{C}$. The detector and injector temperature was $275^{\circ} \mathrm{C}$ and the nitrogen carrier gas flow rate was $35 \mathrm{~cm}^{3} / \mathrm{min}$. An integrator (Supergrator-Columbia Scientific Industries, Austin, Texas, USA) was used to give peak areas and retention times.

\section{Antibiotic susceptibilities}

The following antibiotics were tested: penicillin, ampicillin, tetracycline, erythromycin, gentamicin, cefuroxime, cefotaxime, chloramphenicol and ciprofloxacin. An agar incorporation method of MIC determination was employed with $7 \%$ horse-blood agar containing doubling dilutions of each antibiotic. A multipoint inoculator (Microtitre, Dynatech, Billinghurst, W. Sussex) was used to transfer $0.01 \mathrm{ml}$ of a suspension of $c .10^{6} \mathrm{cfu} / \mathrm{ml}$ of each strain to the antibiotic-containing plates, which were incubated at $37^{\circ} \mathrm{C}$ for $48 \mathrm{~h}$ in an atmosphere containing $\mathrm{CO}_{2} 5 \%$. The lowest antibiotic concentration that inhi- bited growth was recorded as the MIC. The Oxford strain of Staphylococcus aureus (NCTC 6571) was used as the control organism throughout.

\section{$\beta$-Lactamase production}

The chromogenic cephalosporin nitrocefin (Glaxo Ltd, Greenford, Middlesex) was used as described by O'Callaghan et al. (1972) to detect $\beta$-lactamase production.

\section{Results}

The results of tests for acid production from carbohydrates are shown in table I. All strains produced acid from dextrin, D-fructose, D-galactose, glucose and maltose, whereas tests with mannose and salicin gave different results with different strains.

The results of tests of enzymatic activity are summarised in table II. Positive reactions were obtained with all strains for alkaline phosphatase, butyrate esterase, caprylate esterase, myristate lipase, leucine arylamidase, chymotrypsin and acid phosphatase. One strain, NCTC 10773, also showed $\beta$-glucuronidase activity.

Table I. Acid production from carbohydrates by seven strains of $S$. moniliformis

\begin{tabular}{|c|c|c|c|c|c|c|c|c|c|c|c|c|c|c|}
\hline \multirow[b]{4}{*}{ Carbohydrate } & \multicolumn{14}{|c|}{ Results obtained after $3^{*}$ and $7 \dagger$ days with } \\
\hline & \multicolumn{8}{|c|}{ patient isolates } & \multirow{2}{*}{\multicolumn{2}{|c|}{$\begin{array}{c}\text { NCTC } \\
10651\end{array}$}} & \multirow{2}{*}{\multicolumn{2}{|c|}{$\begin{array}{c}\text { NCTC } \\
10773\end{array}$}} & \multirow{2}{*}{\multicolumn{2}{|c|}{$\begin{array}{c}\text { NCTC } \\
11194\end{array}$}} \\
\hline & \multicolumn{2}{|c|}{1} & \multicolumn{2}{|c|}{2} & \multicolumn{2}{|c|}{3} & \multicolumn{2}{|c|}{4} & & & & & & \\
\hline & $3^{*}$ & $7 \dagger$ & 3 & 7 & 3 & 7 & 3 & 7 & 3 & 7 & 3 & 7 & 3 & 7 \\
\hline Adonitol & - & - & - & - & - & - & - & - & - & - & - & - & - & - \\
\hline Arabinose & - & - & - & - & - & - & - & - & - & - & - & - & - & - \\
\hline Dextrin & + & + & + & + & + & + & + & + & + & + & + & + & $\mathrm{w}$ & + \\
\hline Dulcitol & - & - & - & - & - & - & - & - & - & - & - & - & - & - \\
\hline Erythritol & - & - & - & - & - & - & - & - & - & - & - & - & - & - \\
\hline D-Fructose & + & + & + & + & + & + & + & + & + & + & + & + & + & + \\
\hline D-Galactose & + & + & w & w & w & + & + & + & w & w & w & + & + & + \\
\hline Glucose & + & + & + & + & + & + & + & + & + & + & w & + & + & + \\
\hline Inositol & - & - & - & - & - & - & - & - & - & - & - & - & - & - \\
\hline Inulin & - & - & - & - & - & - & - & - & - & - & - & - & - & - \\
\hline Lactose & - & - & - & - & - & - & - & - & - & - & - & - & - & - \\
\hline Maltose & + & + & + & + & + & + & + & + & + & + & + & + & + & + \\
\hline Mannitol & - & - & - & - & - & - & - & - & - & - & - & - & - & - \\
\hline Mannose & - & - & + & + & - & - & - & - & + & + & w & + & + & + \\
\hline Raffinose & - & - & - & - & - & - & - & - & - & - & - & - & - & - \\
\hline Rhamnose & - & - & - & - & - & - & - & - & - & - & - & - & - & - \\
\hline Salicin & - & - & - & w & + & + & - & - & - & - & - & - & $w$ & + \\
\hline Sorbitol & - & - & - & - & - & - & - & - & - & - & - & - & - & - \\
\hline Sucrose & - & - & - & - & - & - & - & - & - & - & - & - & - & - \\
\hline Trehalose & - & - & - & - & - & - & - & - & - & - & - & - & - & - \\
\hline Xylose & - & - & - & - & - & - & - & - & - & - & - & - & - & - \\
\hline
\end{tabular}

$+=$ Strong acid production; $\mathrm{w}=$ weak acid production $;-=$ no acid produced. 
Table II. Enzymatic activities of seven strains of $S$. moniliformis in the API ZYM system

\begin{tabular}{|c|c|c|c|c|c|c|c|}
\hline \multirow[b]{3}{*}{ Enzyme assayed } & \multicolumn{7}{|c|}{ Results* obtained with } \\
\hline & \multicolumn{4}{|c|}{$\begin{array}{l}\text { patient iso- } \\
\text { lates }\end{array}$} & \multirow{2}{*}{$\begin{array}{c}\text { NCTC } \\
10651\end{array}$} & \multirow{2}{*}{$\begin{array}{c}\text { NCTC } \\
10773\end{array}$} & \multirow{2}{*}{$\begin{array}{r}\text { NCTC } \\
11194\end{array}$} \\
\hline & 1 & 2 & 3 & 4 & & & \\
\hline Alkaline phosphatase & 1 & 1 & 2 & 1 & 1 & 1 & 2 \\
\hline Butyrate esterase & 4 & 4 & 4 & 4 & 4 & 4 & 4 \\
\hline Caprylate esterase & 4 & 4 & 4 & 4 & 4 & 4 & 4 \\
\hline Myristate lipase & 1 & 1 & 1 & 1 & 1 & 1 & 1 \\
\hline Leucine arylamidase & 2 & 3 & 2 & 2 & 2 & 2 & 2 \\
\hline Valine arylamidase & 0 & 0 & 0 & 0 & 0 & 0 & 0 \\
\hline Cystine arylamidase & 0 & 0 & 0 & 0 & 0 & 0 & 0 \\
\hline Trypsin & 0 & 0 & 0 & 0 & 0 & 0 & 0 \\
\hline Chymotrypsin & 4 & 5 & 4 & 4 & 5 & 4 & 4 \\
\hline Acid phosphatase & 3 & 3 & 4 & 3 & 3 & 3 & 4 \\
\hline Naphtol-AS-B1-phosphohydrolase & 0 & 0 & 0 & 0 & 0 & 0 & 0 \\
\hline$\alpha$-galactosidase & 0 & 0 & 0 & 0 & 0 & 0 & 0 \\
\hline$\beta$-galactosidase & 0 & 0 & 0 & 0 & 0 & 0 & 0 \\
\hline$\beta$-glucuronidase & 0 & 0 & 0 & 0 & 0 & 3 & 0 \\
\hline$\alpha$-glucosidase & 0 & 0 & 0 & 0 & 0 & 0 & 0 \\
\hline$\beta$-glucosidase & 0 & 0 & 0 & 0 & 0 & 0 & 0 \\
\hline N-acetyl- $\beta$-glucosaminidase & 0 & 0 & 0 & 0 & 0 & 0 & 0 \\
\hline$\alpha$-mannosidase & 0 & 0 & 0 & 0 & 0 & 0 & 0 \\
\hline$\alpha$-fucosidase & 0 & 0 & 0 & 0 & 0 & 0 & 0 \\
\hline
\end{tabular}

* $0=$ Negative, $5=$ strongly positive, $1-4=$ intermediate reaction; all results were read by comparison with the manufacturer's colour charts.

The fatty-acid profiles were consistent in showing three major peaks, tentatively identified from retention times as $\mathrm{C} 16: 0$ (palmitic), merged $\mathrm{C} 18: 2$ (linoleic) and C18:1 (oleic), and C18:0 (stearic). The mean percentages, with ranges, of the total fatty acid content were, respectively, 26\% (23-27), $34 \%(30-42)$ and $17 \%(14-20)$.

The MIC findings are shown in table III. Penicil- lin gave the lowest modal MIC of the antibiotics tested $(0.015 \mathrm{mg} / \mathrm{L})$, followed by ampicillin $(0.03$ $\mathrm{mg} / \mathrm{L})$ and cefuroxime $(0 \cdot 125 \mathrm{mg} / \mathrm{L})$. Cefotaxime and tetracycline showed similar activity with modal values of $0.5 \mathrm{mg} / \mathrm{L}$. Chloramphenicol, gentamicin and erythromycin were the least active of the antibiotics tested, having modal MICs of 8,2 and 2 $\mathrm{mg} / \mathrm{L}$ respectively. Ciprofloxacin, one of the

Table III. MICs of nine antibiotics against seven strains of $S$. moniliformis

\begin{tabular}{|c|c|c|c|c|c|c|c|}
\hline \multirow[b]{3}{*}{ Antibiotic } & \multicolumn{7}{|c|}{$\mathrm{MIC}(\mathrm{mg} / \mathrm{L})$ of the given antibiotic against } \\
\hline & \multicolumn{4}{|c|}{ patient isolates } & \multirow{2}{*}{$\begin{array}{c}\text { NCTC } \\
10651\end{array}$} & \multirow{2}{*}{$\begin{array}{c}\text { NCTC } \\
10773\end{array}$} & \multirow{2}{*}{$\begin{array}{c}\text { NCTC } \\
11194\end{array}$} \\
\hline & 1 & 2 & 3 & 4 & & & \\
\hline Penicillin & $0 \cdot 015$ & 0.0075 & $0 \cdot 015$ & $0 \cdot 015$ & 0.015 & 0.015 & $0 \cdot 015$ \\
\hline Ampicillin & 0.06 & 0.03 & 0.06 & 0.03 & 0.03 & 0.06 & 0.03 \\
\hline Cefuroxime & $0 \cdot 125$ & 0.06 & $0 \cdot 125$ & $0 \cdot 125$ & $0 \cdot 125$ & $0 \cdot 125$ & 0.06 \\
\hline Cefotaxime & 0.5 & $0 \cdot 25$ & 0.5 & $0 \cdot 25$ & 0.5 & $0 \cdot 5$ & $0 \cdot 25$ \\
\hline Tetracycline & $0 \cdot 5$ & 0.5 & 0.5 & 0.5 & 0.5 & $0 \cdot 25$ & 0.5 \\
\hline Ciprofloxacin & 1 & 1 & 2 & 1 & 1 & 1 & 1 \\
\hline Gentamicin & 4 & 2 & 4 & 2 & 2 & 2 & 2 \\
\hline Erythromycin & 2 & 2 & 2 & 2 & 4 & 2 & 4 \\
\hline Chloramphenicol & 8 & 8 & 8 & 8 & 8 & 8 & 8 \\
\hline
\end{tabular}


recently developed quinolones, gave a modal MIC of $1 \mathrm{mg} / \mathrm{L}$. $\beta$-Lactamase activity was not detected in any of the test strains.

\section{Discussion}

S. moniliformis is a pleomorphic, non-acid-fast, gram-negative bacillus characteristically seen in chains or filaments and often displaying bulbous swellings. Serum, ascitic fluid or blood are required for growth and $\mathrm{CO}_{2}$ is necessary for fresh isolates (Whittler and Cary, 1974). Sodium polyanethol sulphonate (Liquoid), commonly used in blood culture systems, inhibits the growth of $S$. moniliformis at concentrations as low as $0.0125 \%$ (Lambe et al., 1973) and may prevent isolation from blood if present in excess in culture systems (Shanson et al., 1983).

The results of tests for acid production from carbohydrates were in agreement with those of Whittler and Cary (1974), with the exception that three of our strains failed to produce acid from mannose. The variability of acid production from mannose and salicin amongst the four isolates from the same outbreak of Haverhill fever is interesting and indicates lack of stability of these characters. Lambe et al. (1973) reported acid production from trehalose, whereas in our study all strains tested gave negative results. The inability to produce acid from fructose was reported by Cohen et al (1968), contrary to the findings of our study. Smith and Sampson (1960) observed acid production from xylose but Whittler and Cary (1974) describe this reaction as variable. None of the strains tested in our study produced acid from xylose. Differences in media composition and incubation conditions may account for these discrepancies.

\section{REFERENCES}

Cohen R L, Whittler R G, Faber J E 1968 Modified biochemical tests for characterization of L-phase variants of bacteria. Applied Microbiology 16:1655-1662.

Lambe DW, McPhedran A M, Mertz J A, Stewart P 1973 Streptobacillus moniliformis isolated from a case of Haverhill fever; biochemical characterization and inhibitory effect of sodium polyanethol sulfonate. American Journal of Clinical Pathology 60:854-60.

Moss C W, Dees S B 1975 Identification of microorganisms by gas chromatographic-mass spectrometric analysis of cellular fatty acids. Journal of Chromatography 112:594-604.

O'Callaghan C H, Morris A, Kirby S M, Singler A H 1972 Novel method for detection of beta-lactamases by using a chromogenic cephalosporin substrate. Antimicrobial Agents and Chemotherapy 1:283-288.

Roughgarden J W 1965 Antimicrobial therapy of rat bite fever. Archives of Internal Medicine 116:39-54.
General consistency of the enzymatic profiles of $S$. moniliformis strains was displayed with the API ZYM system. The fatty-acid profiles were uniform and consistent with the findings of Rowbotham (1983) who used serum broth as the growth medium. The API ZYM system and cellular fatty acid analysis could prove useful for rapid identification of $S$. moniliformis.

Smith and Sampson (1960) reported sensitivity to penicillin and tetracycline but low activity of chloramphenicol against $S$. moniliformis. All three have been used successfully to treat infections with this organism (Roughgarden, 1965). Our in-vitro antibiotic susceptibility findings reveal that penicillin remains the most active agent against $S$. moniliformis. The absence of $\beta$-lactamase activity is consistent with these susceptibilities. These findings support the use of penicillin as the drug of choice in cases of Haverhill fever. Roughgarden (1965) showed a correlation between penicillin dosage and response to therapy with failure occurring when $<400,000$ units/day were used. Good activity was also demonstrated with ampicillin and cefuroxime. Tetracycline was the most active of the non $\beta$ lactam antibiotics tested and this drug would be particularly indicated when there is a history of penicillin allergy. Erythromycin and gentamicin had comparable activity whereas chloramphenicol, although reported as being a useful alternative to penicillin, had the least activity in vitro of the antibiotics tested. Ciprofloxacin is the most active of the quinolone antibiotics currently under investigation, and although the activity against $S$. moniliformis is modest, it again confirms the broadspectrum of activity of these agents (Wise et al. 1983).

Rowbotham T J 1983 Rapid identification of Streptobacillus moniliformis. Lancet 2:567.

Shanson D C et al. Streptobacillus moniliformis isolated from blood in four cases of Haverhill fever. First outbreak in Britain. Lancet 2:92-94.

Smith C D, Sampson C C 1960 Studies of Streptobacillus moniliformis from a case of human rat-bite fever. American Journal of Medical Technology 26:47-50.

Watkins C G 1946 Ratbite fever. Journal of Pediatris 28:429-448. Whittler R G, Cary S G 1974 Genus Streptobacillus Levaditi, Nicolau and Poincloux 1925, 1188. In: Buchanan R E, Gibbons N E (eds). Bergey's manual of determinative bacteriology, 8 th edn. Williams and Wilkins Co., Baltimore, MD pp 378-381.

Wise R, Andrews J M, Edwards L J 1983 In vitro activity of Bay 09867, a new quinoline derivative, compared with those of other antimicrobial agents. Antimicrobial Agents and Chemotherapy 23:559-564. 